\title{
editorial
}

Dra. Carmen Luisa Vásquez

\section{Sistemas de Gestión de Mantenimiento}

Estimados lectores de la Revista REBI, para su comité editorial y nosotros es un placer hacerle llegar este nuestro primer número. El objeto de la Revista es ser un medio de difusión de los resultados originales e inéditos de las investigaciones realizadas por profesores, profesionales y estudiantes elaboradas en las áreas de la ingeniería, tecnología y afines que proporcionan una eminente contribución al conocimiento científico y tecnológico. Esta difusión cuenta el avance y estado del conocimiento, buscando entre otros propósitos, su divulgación y adecuado resguardo. El público al que destinamos la revista es principalmente la comunidad académica y de investigación en Bolivia, América Latina y el mundo.

En el campo de la ingeniería, tecnología y afines se refieren a todo el conocimiento desarrollado, que va más allá de la sola observación del existente, que busca resolver nuestros problemas, mejorar la calidad de vida y lograr el desarrollo de nuestras naciones. Similar al conocimiento científico, se obtiene de manera planificada, objetiva y sistémica (ordenada y lógica), a través de su método, conocido como Método Tecnológico. A su vez, la Ingeniería cuenta con su propio método. Los métodos científicos, tecnológicos y de ingeniería cuentan con una serie de pasos en la búsqueda del conocimiento. En este marco, REBI es un medio de difusión cuyas contribuciones conjugan estos métodos y se muestren como artículos en cada una de sus publicaciones.

El presente número se ha dedicado a la Gestión de Mantenimiento, término que ha transitado de sólo reparar un equipo, para garantizar la continuidad de los procesos, hasta hoy día donde existen modelos predictivos que buscan anticipar su ocurrencia $y$, con esto, disminuir o evitar los costos que se incurren por la paralización. Actualmente, los sistemas de gestión de mantenimientos deben incluir políticas, indicadores, acciones y medidas de mejora que permitan administrar los recursos financieros, tecnológicos, humanos y otros y que le permitan garantizar un adecuado funcionamiento en de los procesos productivos, tanto de bienes como de servicios.

En este número usted encontrará cuatro (4) artículos relacionados con las etapas de los procesos administrativos y planificación estratégica, organización y trabajos preventivos, planificación y, finalmente, indicadores, todos estos aspectos considerados en los sistemas de gestión de mantenimiento modernos en empresas petroleras, de servicio eléctrico y universidades. Como podemos ver es un número con temas y aportes con una diversidad propia de ser analizada por cada uno de nuestros lectores. 